\title{
DISCLAIMER
}
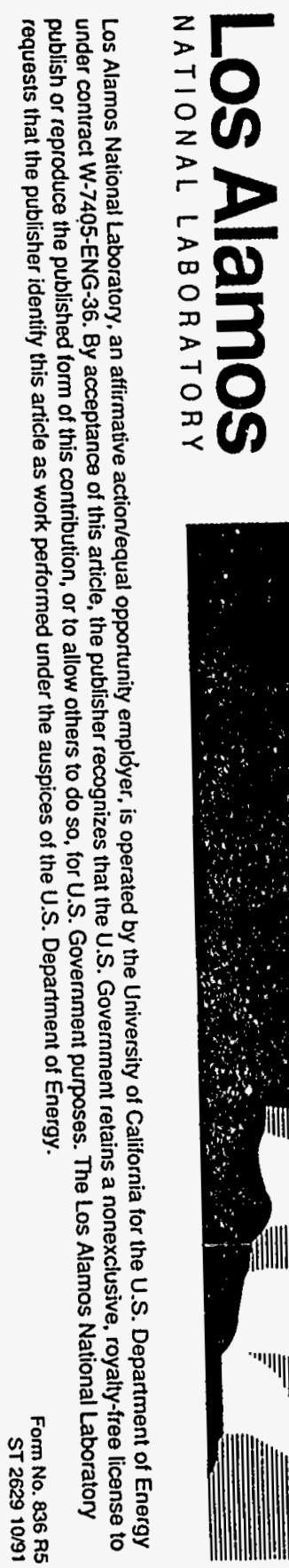

This report was prepared as an account of work sponsored by an agency of the United States Government. Neither the United States Government nor any agency thereof, nor any of their employees, makes any warranty, express or implied, or assumes any legal liability or responsibility for the accuracy, completeness, or usefulness of any information, apparatus, product, or bility for the accuracy, completeness, or usefulness of any information, apparatus, product, or
process disclosed, or represents that its use would not infringe privately owned rights. Reference herein to any specific commercial product, process, or service by trade name, trademark, manufacturer, or otherwise does not necessarily constitute or imply its endorsement, recommendation, or favoring by the United States Covernment or any agency thereof. The views and opinions of authors expressed herein do not necessarily state or reflect those of the United States Government or any agency thereof.
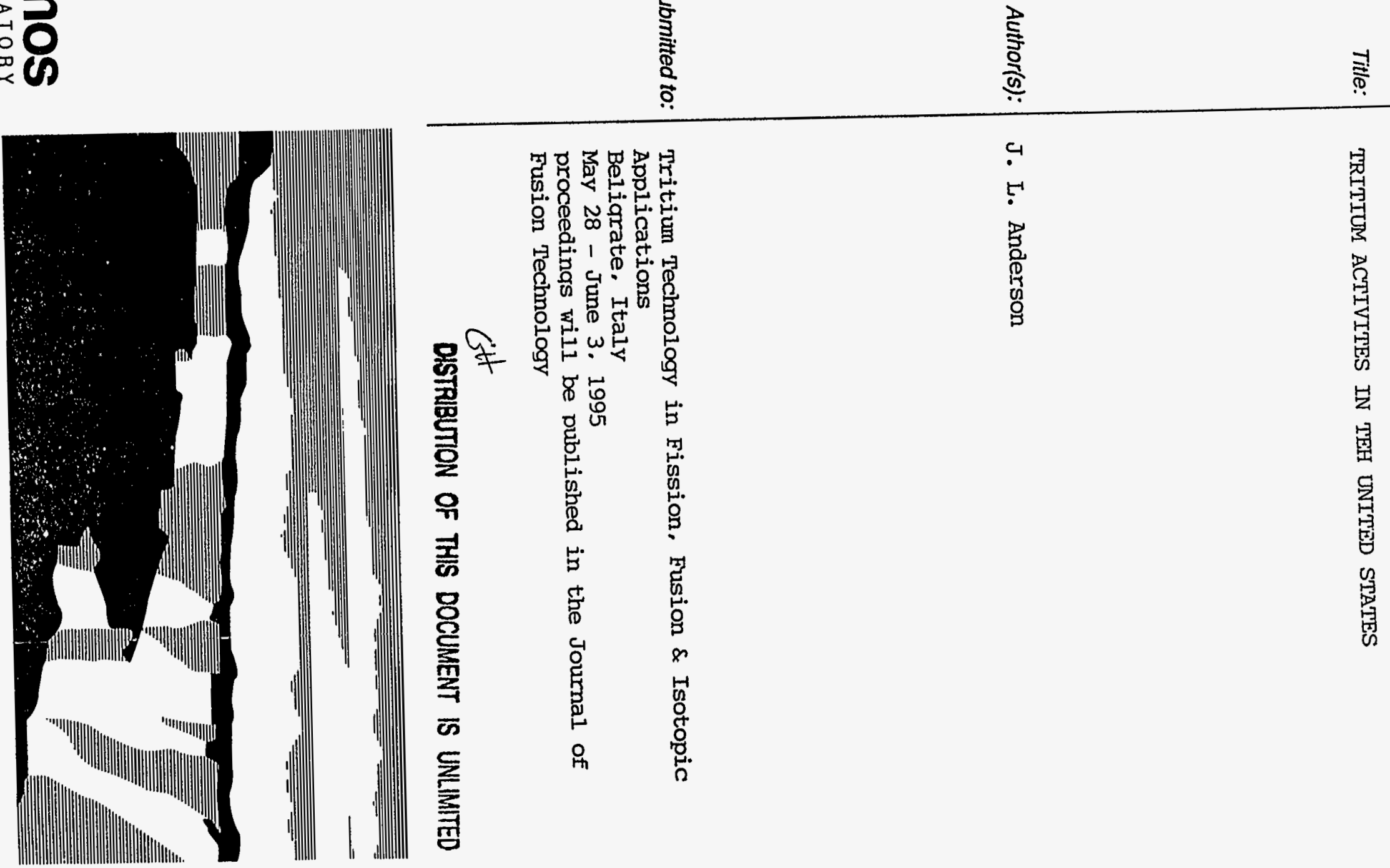

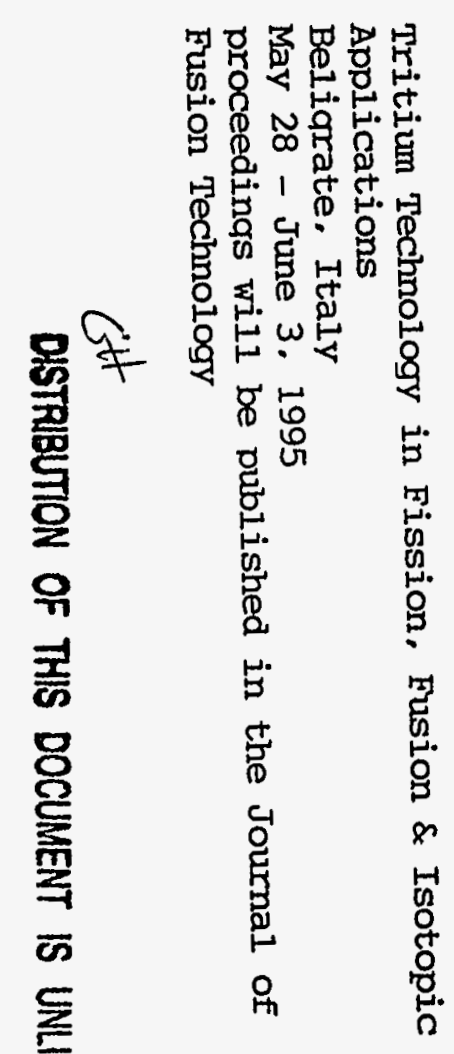




\section{TRITIUM ACTIVITIES IN THE UNITED STATES}

James L. Anderson

Los Alamos National Laboratory

PO Box 1663, MS H813

Los Alamos, NM 87545

(505) 667-1410
Paul LaMarche

Princeton Plasma Physics Laboratory

Princeton University

Princeton, NJ 08543

(609) 243-3244

\section{ABSTRACT}

There have been many significant changes in the status of tritium activities in the US since the 4th Tritium Conference in October, 1991. The Replacement Tritium Facility (RTF) at Savannah River Site and the Weapons Engineering Tritium Facility (WETF) at the Los Alamos - National Laboratory are now operational with tritium. The Tokamak Fusion Test Reactor (TFTR) has initiated a highly successful experimental campaign studying DT plasmas, and has produced more than 10 Megawatts (MW) of fusion power in a D-T plasma. Sandia National Laboratory has ceased tritium operations at the Tritium Research Laboratory (TRL) and many of the activities previously performed there have been transferred to Los Alamos and Savannah River. The tritium laboratory at Lawrence Livermore National Laboratory has reduced the tritium inventory to $<5$ grams. The Tritium Systems Test Assembly (TSTA) at Los Alamos continues to be at the forefront of tritium technology and safety development for the fusion energy program.

\section{INTRODUCTION}

The past few years have been exciting for the US tritium science and technology programs. The Replacement Tritium Facility (RTF) at Savannah River and the Weapons Engineering Tritium Facility (WETF) at the Los Alamos National Laboratory (LANL) have begun full tritium operations. The Tritium Research Laboratory (TRL) at Sandia National Laboratory is in the process of being decommissioned, the Tritium Laboratory at Lawrence Livermore National Laboratory has been downsized to a maximum on-site inventory of 5 grams. The Mound Facility tritium operations have been significantly reduced, with the mission at this facility devoted to tritium cleanup and recovery. Tritium activities at the Tritium Systems Test Assembly (TSTA) at LANL have continued at a busy pace with development and demonstration of a palladium membrane reactor (PMR) concept for use in the ITER fuel cleanup system progressing into tritium testing.

The initiation of full scale deuteriumtritium (DT) operations on the Tokamak Fusion Test Reactor (TFTR) at the Princeton Plasma Physics Laboratory has been one of the major highlights of US tritium activities since the 4th Topical Meeting on Tritium Technology, held in October 1991. Tritium operations on TFTR began in November 1993 and led to a DT plasma pulse producing 6.2 MW of fusion power in December 1993. The DT experimental program on TFTR continued into 1994 and 1995 and has resulted in significant achievements including a DT plasma pulse producing some $10.7 \mathrm{MW}$ of fusion power in November 1994. To date some 360,000 Curies (CI) of tritium have been supplied to the TFTR neutral-beam ion sources. Of this, only about $15 \mathrm{kCi}$ were actually injected into the vacuum vessel as energetic atoms. Of these $15 \mathrm{kCi}$ injected, some $12.7 \mathrm{kCi}$ remain trapped inside the vessel, presumably, most of this in the graphite bumper-limiter.

At TFTR an on-site tritium processing capability, the Tritium Purification System (TPS) has been installed and commissioned. The TPS provides for continuous reprocessing of the plasma exhaust gas, preparing pure tritium for reuse at TFTR and separating the impurities for disposal. 


\section{DISCLAIMER}

\section{Portions of this document may be illegible in electronic image products. Images are produced from the best available original document.}


II. STATUS OF TRITIUM ACTIVITIES AT THE MAJOR DOE TRITIUM SITES

\section{A. Los Alamos National Laboratory}

There are several major tritium facilities in operation at LANL. Work at these facilities encompass nuclear weapons component - evaluation and development, fusion fuel processing and handling development, development of a design for an accelerator based tritium production system, and numerous research and development activities. A brief discussion of major experimental activities at the larger facilities follows.

\section{Weapons Engineering Tritium Facility}

The WETF' was approved for tritium operations in 1992. The facility now has a tritium inventory of a few tens of grams. The major activities at WETF include receiving and unloading tritium from shipping containers into the Tritium Gas Handling Subsystem (TGCS), which is located in the process room; repackaging tritium and other gases contaminated with tritium and preparing these gases for shipment to other sites for additional cleanup and processing; separating helium from tritium; mixing tritium with other gases; and analyzing tritium gas mixtures.

The WETF contains several systems designed to enhance the safety of the facility. These include the Tritium Gas Confinement Subsystem (TGCS), consisting of glovebox sections that confine any tritium escaping from the TGHS and minimize exposure of operating personnel to tritium; a Tritium Waste Treatment Subsystem (TWTS) that processes the TGCS exhaust to extract tritium for either recovery or disposal; an Emergency Tritium Cleanup Subsystem (ETCS) that processes tritium releases to the process or recovery rooms that might result from an accident or other unplanned release; and the Instrumentation and Control System (ICS) that provides the facility operator with real-time data, alarms, and control of process variables.

The major tritium activities at WETF have been related to the Decontamination and Decommissioning (D\&D) of an older High
Pressure (HP) tritium facility at LANL. Excess tritium gas and tritum contaminated gases from HP were brought to WETF where these gas mixtures were consolidated into a few shipping containers. These shipping containers were then to be shipped to TSTA where the gas mixtures would be purified and the tritium recovered using the fuel cleanup system and the isotope separation systems at TSTA. To date, some 30 grams of tritium have been recovered at WETF and shipped to TSTA for recovery.

Tritium Science and Fabrication Facility (TSFF)

The $\mathrm{TSFF}^{2}$ at LANL provides a facility for working with tritium gas and metal tritides. The TSFF includes a large, inert atmosphere glovebox and dry-train, an effluent Treatment System (ETS) and associated hardware. A new, state-of-the-art, high precision mass spectrometer has recently been installed and commissioned. This instrument will provide accurate measurement of hydrogen isotope streams, including isotopic ratios and impurity analysis. This facility has been operational, with tritium, since 1974 and was previously known as the Tritium Salt Facility. This facility can maintain a tritium inventory of several tens of grams.

In 1993 the Department of Energy (DOE) made the decision to close the Marin Marietta Specialty Components Plant in Pinellas, Florida, and to transfer the construction of neutron generators, the Neutron Tube Target Loading (NTTL) project, to SNL and LANL. LANL is responsible for loading the targets used in the generators with tritium. This work is being done at TSFF. In late 1994 the Tritium Science and Engineering group at LANL successfully loaded targets with deuterium. The deuterium loading is a first step in certification of the process and further development will result in tritium loadings in the coming months.

\section{Tritium Systems Test Assembly (TSTA)}

In 1987, the Japan Atomic Energy Research Institute (JAERI) and the US Department of Energy (DOE) signed a 
collaborative agreement (Annex IV) for the joint funding and operation of the Tritium Systems Test Assembly (TSTA) at the Los Alamos National Laboratory (LANL) for a five year period ending June, 1992. After this initial five year collaboration, the Annex IV agreement was extended for another two year period ending June, 1994. In June 1994 the agreement was extended for an additional three year period, but with the second extension the thrust of the collaborative activities changed from Fusion Fuel Processing Development of Fusion Fuel Safety Studies.

During the two year extension of the collaborative agreement at TSTA the programmatic emphasis has been focused on two areas: 1) operating the TSTA loop under conditions simulating the non-steady state conditions expected for an operating tokamak; and 2) operation of TSTA subsystems under conditions typical of those expected in processing product gas from a tritium bleeding blanket.

Large tokamak fusion devices, such as ITER, will operate as pulsed machines, albeit with long pulse lengths. However, even for nominally steady-state machines, transient operations for ramp-up, shut down, discharge cleaning or conditioning and normal operations must all be handled by the fuel processing system. TSTA has begun a series of tests, with the integrated fuel processing loop ${ }^{3}$ to study the response of the fuel processing system to these changing scenarios. Operation of the fuel processing loop with tritium inventories of up to 100 grams and nominal fuel processing rates of up to $390 \mathrm{~g}$ moles/day (tritium processing rates of $1-1.2 \mathrm{~kg} /$ day), have been conducted with variations in flowrate and composition that mimic changes expected for practical pulsed DT torus operations.

\section{a. Isotope Separation System (ISS)}

In order to meet the above objectives major modifications had to be made to the isotope separation system at TSTA. This new ISS configuration more closely resembles the proposed isotope separation system for ITER.
The modifications to the ISS encompassed removing all of the original inter-column connecting piping, flow controllers, valves, etc. and replacing this highly tritium contaminated piping with new and upgraded components. New flow controllers, valves, piping and instrumentation were installed. Also, the first column of the TSTA 4-column cascade has 84 theoretical stages, with 3 alternate feed-injection points. and 7 sample withdrawal locations. This column piping was modified to permit a stream of hydrogen isotopes to be withdrawn from any of the sample taps through a flow control valve, equilibrated over a precious metal catalyst bed at ambient temperature, and pumped back into any other sample tap (sidestream recycle). Figure 1 shows the column layout schematically. These major modifications to a tritium system that had processed more than $10^{9}$ Curies of tritium required developing new procedures and technologies. This included the use of a Cajon ${ }^{\mathrm{TM}}$ Orbital Welder system for welding all of the new piping and components to the existing, tritium contaminated system. The use of the Orbital Welder permitted these modifications to occur in very crowded spaces, without any worker uptake of tritium, and without any significant release of tritium to the room or environment. Extensive pumping and purging of the system before performing any line breaks contributed significantly to the safe accomplishment of these modifications.

Experimental results obtained with the modified ISS, including the sidestream recycle, demonstrate a dramatic effect on the product streams. The sidestream recycle results in higher purity products with fewer columns in the cascade and, therefore, with lower tritium inventories in the system. These results are significant confirmation of this technique as a means of reducing tritium inventory in fusion fuel processing loops.

Other changes that have been applied to the ISS during this period include the addition of more sophisticated control loops. Previously the ISS had been operated in "open loop," i.e. all manual control. This required 
semi-continuous, focused attention to the ISS by an expert or extremely well trained and experienced operator. The new control loops were added to maintain material balances in the column by controlling 1) liquid levels in all four columns, 2) using reboiler heat input to control column $\Delta \mathrm{P}$ on columns $\mathrm{I}$ and $\mathrm{H}$, and 3) controlling the ratio of feed flow to top flow for Columns I, D and T. The effectiveness of the new control system was demonstrated in operation of the TSTA fuel processing loop. Using a nominal 50:50 mixture of DT with impurities of nitrogen, oxygen, helium and hydrogen in the mixture, and a nominal flow rate of $6 \mathrm{l} / \mathrm{m}$ in the loop, it was demonstrated that the ISS could be started up, within a matter of hours, with minimal operator intercession. This demonstration test used all liquid level and ratio controls on the four columns. Once stable operation was achieved loop flow was upset, both up and down by $33 \%$. That is the $6 \mathrm{l} / \mathrm{m}$ flow was lowered to about $4 \mathrm{l} / \mathrm{m}$ and equilibrium reestablished, and later increased to about $8 \mathrm{~J} / \mathrm{m}$ and equilibrium again reestablished. The liquid levels in all columns remained very stable at the selected setpoint.

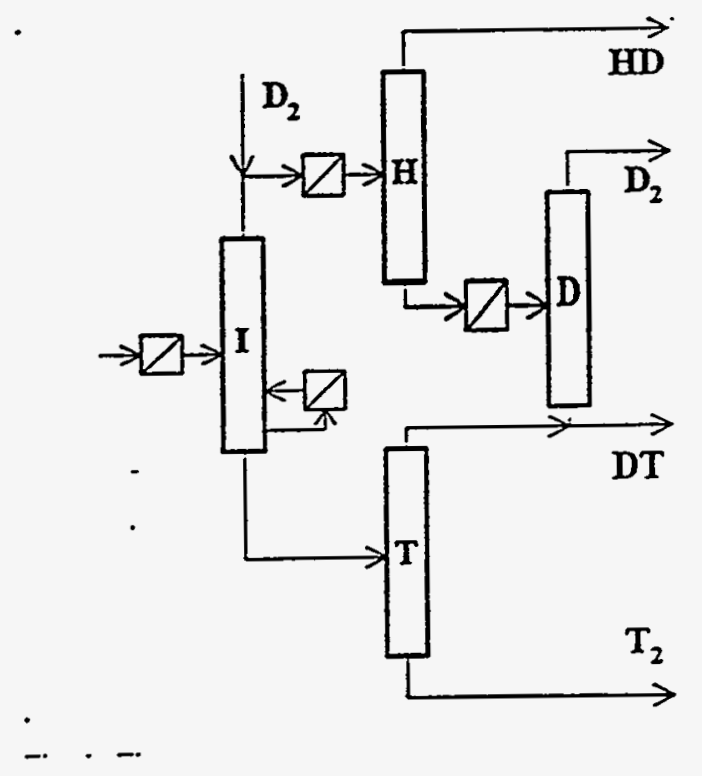

Fig. 1 Flow schematic diagram for the TSTA ISS showing sidestream recycle on column I.

This test was important in establishing the ability of a fuel processing loop to respond, unobtrusively, to rather significant changes in input conditions. An operating tokamak, such as TTER, surely will be subject to this type of large swings in fuel processing inputs. More detailed discussions of these recent results are presented by Sherman, Yamanishi, et al ${ }^{4.6}$.

\section{b. Fuel Cleanup System}

A major study at TSTA during the past two years has been the development of the Palladium Membrane Reactor (PMR) concept for fuel cleanup. This investigation, led by $R$. $S$. Willms, uses a combined catalytic reactor and palladium membrane permeator. In this combination a catalyst is used to promote various reactions leading to the release of hydrogen isotopes from the impurity molecules such as water, methane and other hydrocarbons. Reactions such as water gas shift, steam reforming and methane cracking:

1) $\mathrm{CO}+\mathrm{H}_{2} \mathrm{O} \Leftrightarrow \mathrm{CO}_{2}+\mathrm{H}_{2}$

(water gas shift)

2) $\mathrm{CH}_{4}+\mathrm{H}_{2} \mathrm{O} \Leftrightarrow \mathrm{CO}+3 \mathrm{H}_{2}$

(steam reforming)

3) $\mathrm{CH}_{4} \Leftrightarrow \mathrm{C}+2 \mathrm{H}_{2}$

(methane cracking)

can be carried out over the reactor catalyst, and the product hydrogen can be removed simultaneously from the mixture by permeating through the palladium membrane. Because the reaction product is removed continuously, conversions greater than calculated from thermodynamic equilibrium can be obtained. In addition, an ultra pure hydrogen stream is produced eliminating the need for an additional processing step between this component and the isotope separation system. A palladium membrane reactor has been built and tested at TSTA. The results show that a nickel catalyst, operating at about $600^{\circ} \mathrm{C}$ is very effective at promoting all three reactions listed above.

Initial tritium testing of the PMR with a hydrogen isotope stream containing $5-80 \%$ tritium, with tritiated methane, tritiated water 
and carbon monoxide addition to the hydrogen stream yielded a Decontamination Factor (DF, defined as the ratio of total tritium in the feed stream to total tritium in the retentate) of 200$400^{\circ}$ when the PMR was operated at $500^{\circ}$ $560^{\circ} \mathrm{C}$. These tests are very preliminary and additional tritium testing will occur in the coming months. While preliminary, these first tritium tests are extremely encouraging for use of the PMR in an TTER type fuel cleanup system.

\section{c. Tritium Plasma Experiment (TPE)}

The TPE has recently been upgraded and transferred from the Tritium Research Laboratory (TRL) at SNL to the TSTA at LANL. This transfer occurred as part of the decommissioning of the TRL. TPE ${ }^{9}$ is a unique facility devoted to experiments on the migration and retention of tritium in fusion reactor materials. The TPE has now been installed at TSTA and tritium experiments are schedule to begin in the summer of 1995. The initial experiments on TPE will concentrate on beryllium, the material presently selected as the baseline for the ITER walls and divertor.

\section{B. Savannah River Site}

\section{Replacement Tritium Facility (RTF)}

The RTF was described in detail by Motyka $^{10}$ at the 4th Topical Meeting on Tritium Technology. The RTF was designed and built to handle kilogram quantities of tritium. Tritium activities at the RTF were started in January 1994. All design objectives were successfully demonstrated during early operations. By mid-1994 the RTF was at essentially full operation.

The RTF was designed to take advantage of the latest technology to enhance operational safety, increase safeguards and security, and to minimize tritium releases to the environment. The facility is located below grade to help prevent unauthorized entry. Thick reinforced concrete outer walls combined with redundant safety systems provide protection against natural disasters such as tornadoes and earthquakes and assure that the facility can be safely shutdown with no threat to the environment.

The most significant new technology incorporated into the facility is metal hydride (tritide) technology. Metal hydrides are used extensively in the RTF for storage, separation, purification, pumping, and compression of hydrogen isotopes. The application of metal hydrides to tritium processing has led to several major benefits in the RTF including: better overall procesś confinement; reduced risk of accidental tritium release; increased process reliability; and reduced "hot" maintenance. Metal hydride technology has played a major role in the design and operation of RTF. This role of metal hydrides in tritium processing and handling is expected to continue into the twenty-first century.

\section{Princeton Plasma Physics}

Laboratory

Tokamak Fusion Test Reactor (TFTR)

The deuterium-tritium (DT) experimental program on the Tokamak Fusion Test Reactor (TFTR) started in November 1993.11.12.13 The development and demonstration of this technology at TFTR is the result of a concerted effort by a large number of people at TFTR with input and assistance from a number of other laboratories. The application at TFTR of modern tritium technology and components as developed and evaluated by tritium laboratories within the US Department of Energy has been extremely important to the successes at TFTR. The tritium technology and expertise developed by the Los Alamos National Laboratory's Tritium Systems Test Assembly (TSTA) and at the Westinghouse Savannah River Site contributed considerably to the successful commissioning and operation of the tritium facilities at TFTR. The application of the unique technologies and experience from TSTA, Savannah River and TFTR will certainly impact the final design of the tritium handling systems for ITER.

Since December 1993 the TFTR tritium systems routinely have supported DT operations and have undergone several stages 
of modifications and upgrades to resolve operational problems and concerns uncovered during early tritium operations. ${ }^{14.15}$ The tritium inventory limit of $50,000 \mathrm{Ci}$ creates special tritium handling and inventory/accountability problems. At present, TFTR operations are constrained by the frequency of tritium shipments off-site and the sequential delivery of additional tritium from the supplier. TFTR operations are scheduled around an on-site delivery of about $30 \mathrm{kCi}$ of tritium every two weeks, and a corresponding shipment of tritiated water offsite.

Figure 2 shows the flow path for tritium into and out of the vacuum vessel. The tritium is received in low pressure, 50 liter canisters from Savannah River Site. Each canister contains $16-18 \mathrm{kCi}$ of tritium which is transferred onto a uranium bed in the tritium storage and delivery system (TSDS). When needed to fuel TFTR tritium is desorbed from the uranium bed by heating to approximately $400^{\circ} \mathrm{C}$. The tritium is compressed to about $2.6 \mathrm{bar}$, analyzed for purity and subsequently expanded into the tritium gas delivery manifold (TGDM), a coaxial capillary line which delivers tritium to the tritium injector assemblies. . The tritium is supplied by the TGDM to the Tritium Gas Injection Assemblies (TGIAs) and the NB Tritium Gas Injectors (NBTGI), Fig. 2. The two TGIA provide direct injection of tritium gas into the torus. These have been used for transport studies but are rarely used for fueling plasma discharges (shots).

The primary method for fueling TFTR plasma discharges is by the Neutral Beam Injectors (NBI). Each of the four neutral beams has three ion sources. Any combination of ion sources can be used for each pulse. For a typical DT plasma discharge six of the twelve ion sources are fueled with tritium and the other six are fueled with deuterium. The tritium inventory in the sources prior to the shot is $\approx 5-6 \mathrm{kCi}$. The gas is injected into the ion source, where a fraction is accelerated and a larger fraction enters the neutral beam line and acts to neutralize about one-half of the accelerated beam. The neutral beam line enclosures contain boiling liquid helium cooled cryopanels that pump more than $95 \%$ of the gas injected into the ion source. This means that less than $5 \%$ of the gas delivered to the source for a shot is actually injected into a plasma discharge. Subsequent to the pulse the cryopanels pump the gas particles from the discharge along with any impurities that were generated. During the time between shots, the ion sources are conditioned every 2.5 minutes using pulses of deuterium gas, which is also collected on the cryopanels. Because of this extensive conditioning, the fraction of the total gas that is injected into the beam line is only about $1 \%$ tritium.

Once operation of the machine is complete for the day, the neutral beam cryopanels are regenerated by warming them up to a temperature where the hydrogenic species are evaporated and pumped into the Gas Holding Tanks (GHTs) in the tritium area.

Gas from the torus is directly pumped to the GHTs through the Torus Vacuum Pumping System (TVPS). This system is only used during non-operational periods, being valved off during plasma discharge operations and, hence, a very small fraction $(\approx 1 \%)$ of the gas from the torus, primarily outgassing, is transported to the holding tanks via the TVPS. Another channel to the GHTs is through the several diagnostic devices that are open to the torus during plasma discharge operation. The aggregate gas load from these Diagnostic Vacuum Systems (DVS) is small $(<1 \%)$ due to the limited conductance of these systems to the torus.

The gas in the GHTs is composed of the regenerated fueling gas ( $99 \%$ deuterium, $1 \%$ tritium) and assorted other impurity gas such as nitrogen (from purging) and hydrocarbons generated in the tokamak. The gases are pumped from the GHTs into the Torus Cleanup System (TCS) where the process gas is passed over a catalyst, which oxidizes the active components, forming moisture. The process stream is then passed through Disposable Molecular Sieve Beds (DMSBs). The moisture, containing the tritium oxide is deposited on the DMSB. The gas is passed over a second DMSB and through a large fixed molecular sieve bed. This ensures that only a small fraction of the 


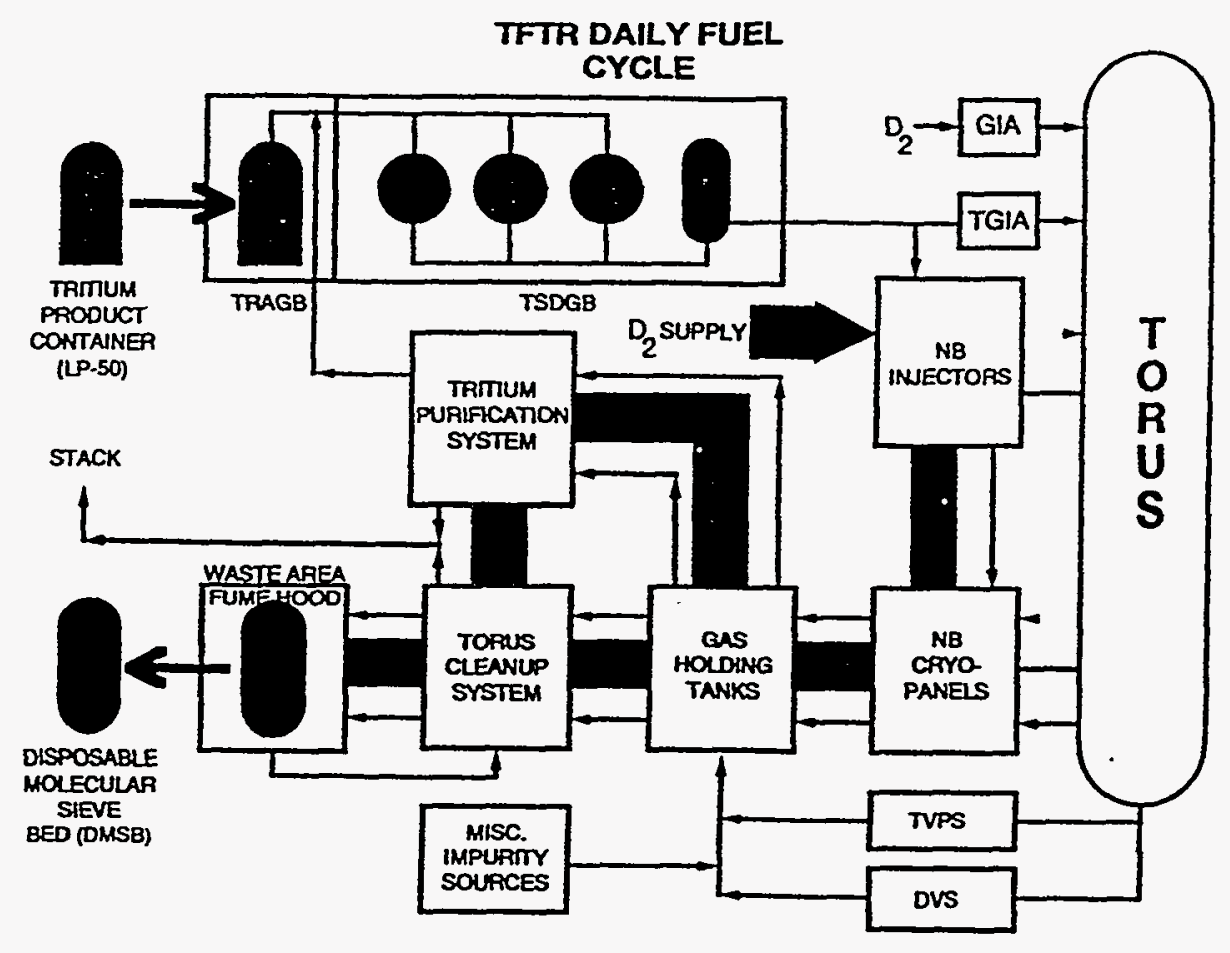

Figure 2. Projection view of the TFTR Tritium Systems. The TSDS is located in the basement in the Tritium Vault. A coaxial line carries the tritium to the two TGIAs for direct injection into the torus and to the 12 ion sources, three on each neutral beam (NB). For a typical DT shot $\approx 5 \mathrm{kCi}$ of tritium is loaded into six of the NBI and the remaining six are charged with deuterium. Line widths indicate relative flow rates of the gaseous species:

original tritium remains in the process stream (<0.1\%.) A small amount of the de-tritiated process gas is then vented to the stack. The process gas is then returned to the start of the TCS loop.

There are two types of DMSBs: Type $A$, which is used to bury the tritium waste has a limit of $1 \mathrm{kCi}$ of tritium and $3.6 \mathrm{~kg}$ of water; and Type B, which is used to store the tritium until it is removed and reprocessed at the Savannah River Site. The Type B DMSB has a limit of $25 \mathrm{kCi}$ of tritium and $3.2 \mathrm{~kg}$ of water.
During peak tokamak operating periods more than $15 \mathrm{kCi}$ can be used during a single 8 hour operating shift. Therefore, the scheduling of several consecutive activities must be carefully orchestrated: tritium must be delivered from the TSDS and used by the neutral beams; neutral beams must be regenerated; the exhaust gas must be processed through the TCS; a loaded DMSB must be removed and packaged for off-site shipment; a new DMSB installed; and a new tritium canister must be installed and tritium transferred to the TSDS. 
In the period December 1993 through March 1995 , some $360 \mathrm{kCi}$ of tritium have been delivered to the TFTR tritium injectors. Approximately $4 \%$ of this total was introduced into the torus, mainly through the energetic neutral beams. ${ }^{16}$ Some $470 \mathrm{kCi}$ of tritium has been collected as oxide, on the DMSBs and shipped off-site for eventual recovery of the tritium. The off-site shipment number includes several $\mathrm{kCi}$ of tritium that were used in commissioning, testing, and calibration activities at TFTR.

Since December 1993 a number of operational problems have been identified and corrected. The most serious problems have resulted from an unexpected introduction of $\mathrm{SF}_{6}$ into the Torus Cleanup System. This material caused a loss of efficiency in tritium recovery in the cleanup system. Even with the degradation of the catalyst activity, the cleanup system continues to operate within original specifications and requirements. These results are important for the designers of future tritium burning fusion devices. The elimination of $\mathrm{SF}_{6}$ as an insulating gas for the power systems in these facilities is strongly suggested. Maintenance and calibration activities have resulted in well over a hundred routine interventions (line breaks) into the primary containment of tritium systems and/or components. Techniques have been developed and procedures prepared such that these line breaks can be made with virtually no tritium release and with no detectable uptake of tritium by the workers. The Project has maintained a very low total uptake of tritium by the TFTR operating staff. The total quantity of tritium released to the environment through the plant stack has been extremely small, $<1 \%$ of the allowable release during the first 3 months of 1995, and current data show that the tritium releases are dropping as more experience and operating time are accumulated.

Scientists at TFTR achieved a record 10.7 Megawatts of fusion power in early November, 1994 and sustained a power of over $10 \mathrm{MW}$ for 0.1 seconds. The input neutral beam heating power was $39.5 \mathrm{MW}$, central electron density was $10^{14} \mathrm{~cm}^{-3}$ central ion temperature was $32 \mathrm{keV}$ and confinement time was 0.21 second. This experiment represented a major TFTR milestone of producing $10 \mathrm{MW}$ of fusion power before the end of 1994.

In October 1994 a decision was made to install the Tritium Purification System (TPS) at TFTR. The TPS is an on-site tritum processing system designed to separate and recycle unburned tritium from TFTR and to produce hydrogen and deuterium streams that are free of tritium, and which, therefore can be disposed by stacking, thus eliminating the need to create large volume waste streams that are contaminated with tritium and that must be shipped off-site in DMSBs. The TPS is designed to have a tritium inventory of $<1$ gram while producing high purity tritium. ${ }^{17}$

The TPS is comprised of the Feed Treatment System, the Cryogenic Distillation System and its supporting instrumentation, controls, alarms, interlocks and computer system. The flow path interfaces with TFTR systems is shown in Fig. 2. Figure 3 shows the flow schematic for the Feed Treatment System.

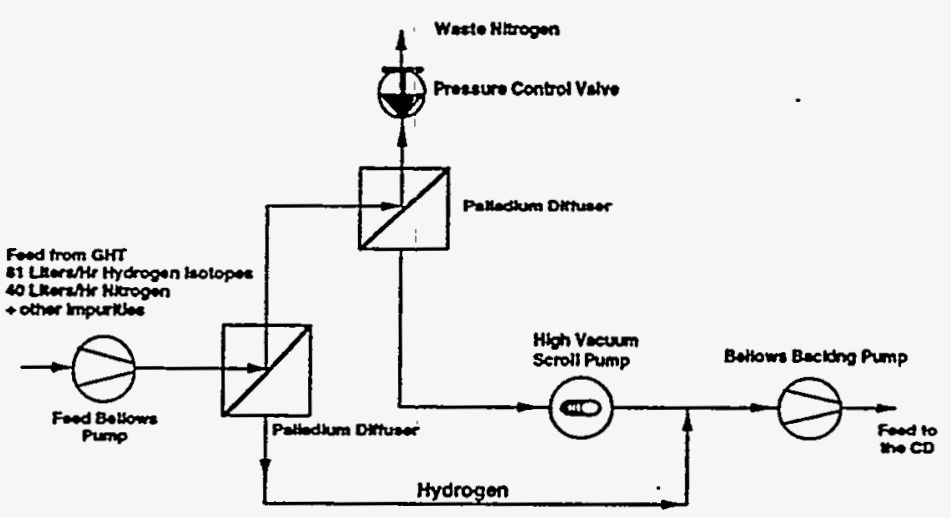

Fig. 3. Flow schematic for the TPS Feed Treatment System

When the TPS is in full operation, the processing path, starting with the injection of 
tritium into the tokamak via the neutral beam injectors or the Tritium Gas Injection System , the plasma exhaust gasses from the tokamak are routed through the Diagnostic Vacuum System, the Neutral Beam Vacuum System or the Torus Vacuum Pumping System to the Gas Holding Tanks (A or B). The exhaust gases are then fed to the Feed Treatment System (FTS) as a crude feed stream containing a mixture of gasses (e.g. hydrogen, argon, nitrogen, tritium and deuterium) This crude stream is passed through two palladiumsilver alloy permeators where the hydrogen isotopes are removed by permeation through the alloy.. The waste feed stream, containing non-hydrogenous gasses is sent to the TCS for processing or back to the Gas Holding Tanks and recycled.

The pure hydrogen feed stream is sent to the Cryogenic Distillation System (CD) for processing. The CD contains four distillation columns operating at cryogenic temperatures in the $20-30 \mathrm{~K}$ range. Helium compressors provide the required cryogenic temperatures. The hydrogen feed stream is processed in the columns utilizing multiple stage distillation columns with product draw-off and side stream recycle at various stages in the columns. The feed stream is separated into hydrogen, deuterium and tritium streams. The tritium fraction is routed to the Tritium Storage and Delivery System for accurate measurement and storage on the uranium beds, and later reuse as fuel for the fusion process. The hydrogen and deuterium are sent to the stack (if tritium levels are sufficiently low) or may be sent to the TCS for processing, or are returned to the Gas Holding Tanks for recycle. Figure 4 is the flow schematic for the cryogenic distillation system.

\section{In March 1995 an Operational
Readiness} commissioning of the TPS successfully was conducted. Initial tritium testing of the TPS will occur in the spring and summer of 1995. These initial tests will be extremely important in determining the equilibrium tritium inventory in the system. If this inventory is less than 1 gram, as designed, the system can make major contributions to the experimental program at TFTR. One of the most important results from the operation of TPS will be the first demonstration of on-site, real-time processing of plasma exhaust gases. These data will be extremely important to the ITER Tritium Plant designers.

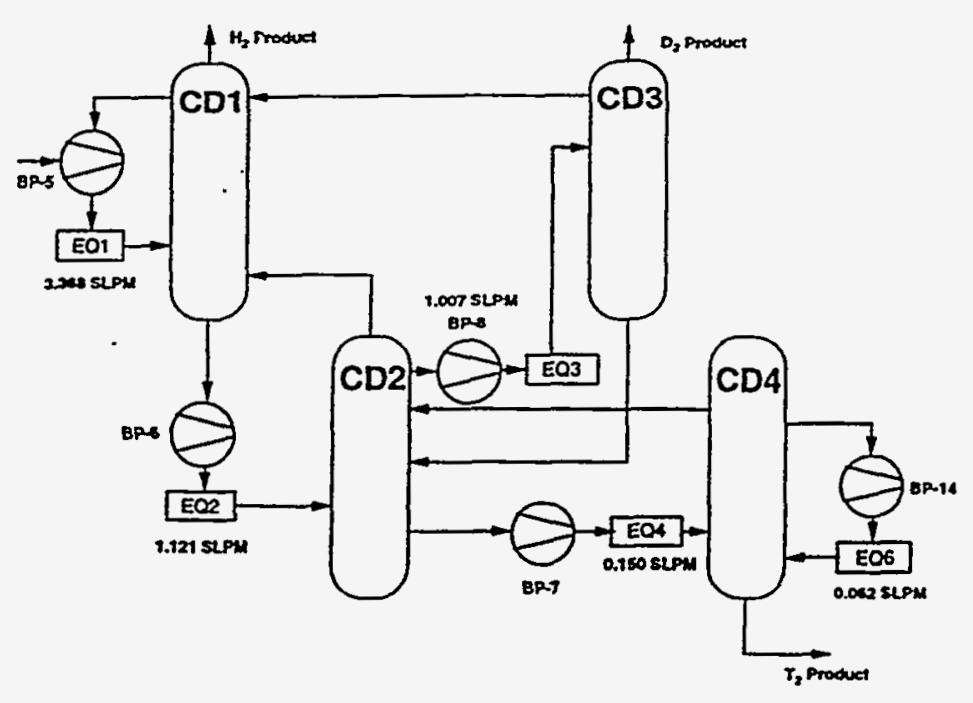

Fig. 4. Flow schematic diagram for the TPS Cryogenic Distillation System.

\section{CONCLUDING THOUGHTS}

The tritium programs in the US continue to make major contributions to the science and technology data base. In the past four years three major tritium facilities have been commissioned in the US, the WETF at LANL, the RTF at Savannah River and the TFTR tritium system at Princeton. During this period tritium facilities at Sandia National Laboratory have ceased operations and tritium facilities at Mound and Lawrence Livermore National Laboratory have seen the scope of activities and tritium inventories reduced significantly. The resulting consolidation of DOE tritium activities at two major sites, Los Alamos and Savannah River, is expected to result in more efficient and more closely coordinated programs and operations.

The continued operation of TFTR at Princeton is anticipated. However, as of this date there is no assurance that DOE will continue to support TFTR operations after September 1995. The installation of the TPS at Princeton can result in more efficient 
operations, if indeed the TPS can operate at the low tritium inventory predicted. This system will allow TFTR operations to be conducted in a more efficient manner. If, however, the equilibrium tritium inventory in the TPS is higher than predicted, the TFTR staff may choose to continue to process plasma exhaust gas through the TCS and collect all of the tritium as water on the DMSBs and ship off-site for recovery. This would allow for operations as usual at TFTR, but will not provide the fusion program with on-site tritium processing data. The accumulation of the first on-site tritium processing experience will provide the ITER program with additional valuable operating experience.

The development of a new tritium production source in the United States is anticipated to be approved in the coming few months. An accelerator based production facility is being considered in lieu of a fission reactor. ${ }^{18}$ The selection of the new production technology will lead to the design and construction of a new tritium extraction facility within the DOE complex. At this time, no other new tritium facilities are anticipated within the US program.

\section{Acknowledgments}

I have called on a number of colleagues to provide input to this paper. While it is impossible to name all of those who have contributed, I gratefully acknowledge the contributions of the many tritium scientists, engineers, facility operators and technicians who have worked hard to maintain the high quality of the US tritium program.

\section{REFERENCES}

1. R. L. Nolen, B. J. James, R. L. Hemphill, and M. E. Fuehrer, "A New Tritium FacilityThe Weapons Engineering Tritium Facility at Los Alamos National Laboratory," Fusion Technol., 14, 947, (1988).

2. J. E. Nasise, "Some New Techniques in Tritium Gas Handling as Applied to Metal Hydride Synthesis," Fusion Technol., 14, 744 (1988).
3. S. Konishi, R. H. Sherman, et al. "Operation of a Simulated Non-Steady Fuel Loop Using the Tritium System Test Assembly," Proc., 3rd Internat. Symp. on Fusion Nucl. Technol., Los Angeles, CA. June 27-July 1, 1994, to be published in Fusion Eng. and Design..

4. R. H. Sherman, T. Yamanishi, et al., "Application of Sidestream Recycle to the Separation of Hydrogen Isotopes by Cryogenic Distillation,"ibid., pp. 77-79.

5. R. H. Sherman, T. Yamanishi, et al., "The Role of Sidestream Recycle in Hydrogen Isotope Separation and Column Cascade Design," Proc. 3rd Internat. Symp. on Fusion Nucl. Technol., Los Angeles, CA, June 27-July 1, 1994.

6. R. S. Willms, R. H. Sherman, S. P. Cole, J. B. Briggs and K. Okuno, "Demonstration of Regulatory Process Controls on the TSTA Cryogenic Distillation System," Presented at 5th Topical Meeting on Tritium Technology in Fission, Fusion and Isotopic Applications, Beligrate, Italy, May 28-June 3, 1995, and to be published in this issue of Fusion Technol.

7. R. S. Willms and $\mathrm{K}$. Okuno, "Recovery of Hydrogen from Impurities Using a Palladium Membrane Reactor," Proc. of 15th IEEE/NPSS Symp. on Fusion Engin., Hyannis, MA, Oct. 11-15, 1993, pp. 85-90.

8. R. S. Willms, S. A. Birdsell and R. C. Wilhelm, "Testing of an Inside-Out Palladium Membrane Reactor," Presented at 5th Topical Meeting on Tritium Technology in Fission, Fusion and Isotopic Applications, Beligrate, Italy, May 28-June 3,1995, and to be published in this issue of Fusion Technol.

9. R. A. Causey and B. Anderl, "Recent Results from the Tritium Plasma Experiment," Presented at 5th Topical Meeting on Tritium Technology in Fission, Fusion and Isotopic Applications, Beligrate, Italy, May 28-June 3, 1995 , and to be published in this issue of Fusion Technol.

10. T. Motyka, "The Replacement Tritium Facility," Fusion Technol., 21, 247, (1992). 
11. Strachan, J. D., et al., "Fusion Power Production from TFTR Plasmas Fueled with Deuterium and Tritium," Phys. Rev. Lett., 72, 3527 (1994).

12. Hawryluk, R. J., et al., "Confinement and Heating of a Deuterium-Tritium Plasma," Phys. Rev. Lett., 723530 (1994).

13. Hosea, J., et al., "Deuterium-Tritium Experiments on the Tokamak Fusion Test Reactor," Fusion Technol., 26, 389, (1994).

14. LaMarche, P. H., et al., "Tritium Processing and Management during D-T Experiments on TFTR," Fusion Technol., 26, 427, (1994).

15. Anderson, J. L., et al., "Operation of the TFTR Tritium Systems during Initial Tritium Experiments," (Proc. 3rd Internat. Symp. on Fusion Nucl. Technol., Los Angeles, 1994) to be published in Fusion Eng. and Design.

16. Von Halle, A., et al., "The Tritium Operations Experience on TFTR," Proc. of 18th Symp. on Fusion Technol., Karlsruhe, Germany, 1994) to be published.

17. A. Busigin, et al., "Installation and Early Operation of a Complex Low Inventory Cryogenic Distillation Column System for the Princeton TFTR," Presented at 5th Topical Meeting on Tritium Technology in Fission, Fusion and Isotopic Applications, Beligrate, Italy, May 28-June 3, 1995, and to be published in this issue of Fusion Technol.

18. B. L. Boggs and R. L. Steinhoff, "An Approach to Tritium Production Using a Linear Proton Accelerator," Presented at 5th Topical Meeting on Tritium Technology in Fission, Fusion and Isotopic Applications, Beligrate, Italy, May 28-June 3, 1995, and to be published in this issue of Fusion Technol. 